\section{Kidney \\ Blood Pressure Research}

Kidney Blood Press Res 2014;39:573-580

DOI: $10.1159 / 000368470$

Publishea onine: vecember 15, 2014

Accepted: November 14, 2014

\title{
Effects of Spironolactone in Combination with Angiotensin-Converting Enzyme Inhibitors or Angiotensin Receptor Blockers in Patients with Proteinuria
}

\author{
Ha Yeon Kim Eun Hui Bae Seong Kwon Ma Soo Wan Kim \\ Department of Internal Medicine, Chonnam National University Medical School, Gwangju, Korea
}

\section{Key Words}

Spironolactone $\cdot$ Proteinuria $\bullet$ Aldosterone escape

\begin{abstract}
Background/Aims: This study aimed to investigate the potential beneficial anti-proteinuric effect of an add-on aldosterone blockade and the impact of the aldosterone escape phenomenon. Methods: We retrospectively analyzed data of 304 patients with persistent proteinuria, who were administered spironolactone $(25 \mathrm{mg} /$ day) after treatment with angiotensin-converting enzyme inhibitors (ACEIs) or angiotensin II receptor blockers (ARBs) for $>3$ months. Patients were divided according to their aldosterone levels during ACEI/ARB treatment into an escape group (plasma aldosterone $>80 \mathrm{pg} / \mathrm{mL}, \mathrm{N}=95,31.5 \%$ ) and a nonescape group (plasma aldosterone $\leq 80 \mathrm{pg} / \mathrm{mL}, \mathrm{N}=209,68.5 \%$ ) and according to their urine albumin-to-creatinine ratio (UACR) and estimated glomerular filtration rate (eGFR). Results: After 12 months, the UACR decreased significantly in patients with $1 \leq \mathrm{UACR}<3.5 \mathrm{~g} / \mathrm{g} \mathrm{Cr}$, UACR $\geq 3.5 \mathrm{~g} / \mathrm{g} \mathrm{Cr}$, and eGFR $\geq 60 \mathrm{~mL} / \mathrm{min} / 1.73 \mathrm{~m}^{2}$, and in the non-escape group. Severe hyperkalemia $(\mathrm{K} \geq 7.0 \mathrm{mEq} / \mathrm{L})$ developed in 9 of 137 patients with eGFR<60 mL/min/1.73 $\mathrm{m}^{2}(6.5 \%)$ and in none of the 167 patients with eGFR $\geq 60 \mathrm{~mL} / \mathrm{min} / 1.73 \mathrm{~m}^{2}$. Conclusions: Proteinuria decreased significantly after add-on spironolactone treatment in patients with $1 \leq \mathrm{UACR}<3.5 \mathrm{~g} / \mathrm{g} \mathrm{Cr}, \mathrm{UACR}$ $\geq 3.5 \mathrm{~g} / \mathrm{g} \mathrm{Cr}$, and eGFR $\geq 60 \mathrm{~mL} / \mathrm{min} / 1.73 \mathrm{~m}^{2}$, and in the non-escape group. The anti-proteinuric effect of spironolactone may vary according to the degree of albuminuria, impaired eGFR, and aldosterone escape.
\end{abstract}




\section{Kidney Blood Pressure Research}

\section{Introduction}

Proteinuria and albuminuria are independent predictors of kidney disease progression [1]. The renin-angiotensin system (RAS) has long been known to play an important role in the pathogenesis of chronic kidney disease [2], and hence, current standards of practice recommend blockade of the RAS with angiotensin-converting enzyme inhibitors (ACEIs) and angiotensin II receptor blockers (ARBs) [3, 4]. However, additional treatment is needed as RAS blockade with ACEIs or ARBs attenuates but fails to abrogate progressive kidney disease [4].

Several studies have reported an increase in plasma aldosterone levels in a substantial portion of patients who were given RAS blockers over the long-term-after an initial decline [5-7]. This phenomenon, known as aldosterone escape, could have important clinical consequences since aldosterone by itself, independent of the RAS, is an important pathogenic factor in progressive kidney disease [8,9]. In this context, adding mineralocorticoid receptor (MR) blockers to conventional RAS blockers has been suggested as an alternative treatment plan. However, no comparison studies between patients with and without aldosterone escape have been published.

Spironolactone has been commonly used in patients with liver cirrhosis or proteinuria in combination with ACEIs or ARBs, with proven effectiveness and safety after a long-term follow-up [10]. The well-documented mechanisms of spironolactone include glomerular hemodynamic change, pro-fibrotic and pro-inflammatory effects, and direct effects on podocytes [11]. Although the anti-proteinuric effect of spironolactone is well known, prophylactic treatment with spironolactone is not recommended in every patient with proteinuria because of the risk of hyperkalemia and a decline in the estimated glomerular filtration rate (eGFR) $[12,13]$.

The aim of this retrospective study was to investigate the potential beneficial antiproteinuric effects of spironolactone and the impact of the aldosterone escape phenomenon.

\section{Materials and Methods}

\section{Study population}

We retrospectively analyzed the data of 304 patients who visited the kidney out-patient department of Chonnam National University Hospital from March 2012 to December 2013. This study was approved by the institutional review board of Chonnam National University Hospital, Gwangju, Korea (CNUH-2013-135). This institutional review board waived the need for consent given the retrospective design of the project.

We studied the effects of spironolactone (25 mg/day) in 304 patients who showed persistent proteinuria after treatment with ACEIs or ARBs for more than 3 months. As per the findings of a recent study [1], our hospital's practice pattern was to add spironolactone in the presence of persistent proteinuria (urine albumin-to-creatinine ratio [UACR] of $>100 \mathrm{mg} / \mathrm{dL}$ or urine dipstick $\geq 1+$, if UACR was unavailable), despite treatment with conventional RAS blockers. The chemical profiles, including UACR, were checked every 3 months to quantify the proteinuria.

Systolic and diastolic blood pressure, plasma aldosterone level, plasma renin activity, serum potassium, eGFR, and UACR were assessed at baseline, and at 6 months and 12 months after spironolactone add-on treatment. Other variables including age, sex, pre-existing diabetes, and spironolactone complications were also investigated. Serum creatinine levels were analyzed using the Jaffe method calibrated for isotope dilution mass spectrometry. The eGFR was calculated using the Chronic Kidney Disease Epidemiology Collaboration (CKD-EPI) equation as follows: $\mathrm{mL} / \mathrm{min} / 1.73 \mathrm{~m}^{2}=141 \times$ minimum (creatinine $\left./ \mathrm{k}, 1\right)^{\alpha} \times$ maximum (creatinine $/ \mathrm{k}, 1)^{-1.209} \times 0.993^{\text {age }} \times 1.018$ (if female) $\times 1.159$ (if black), where $\kappa$ is 0.7 for women and 0.9 for men and $\alpha$ is -0.329 for women and -0.411 for men [2].

Patients were divided into two groups according to their aldosterone levels during treatment with ACEIs or ARBs (an aldosterone escape group [plasma aldosterone $>80 \mathrm{pg} / \mathrm{mL}, \mathrm{N}=95,31.5 \%$ ] and an aldosterone non-escape group [plasma aldosterone $\leq 80 \mathrm{pg} / \mathrm{mL}, \mathrm{N}=209,68.5 \%$ ]). Aldosterone escape was defined as plasma aldosterone level $>80 \mathrm{pg} / \mathrm{mL}$ after treatment with ACEIs or ARBs for more than 3 months 


\section{Kidney \\ Blood Pressure Research}

Table 1. Demographic and clinical data at baseline according to group characteristics

\begin{tabular}{|c|c|c|c|c|c|c|c|c|}
\hline & Total & $\begin{array}{l}\text { UACR <1 } \\
\text { (g/g Cr) }\end{array}$ & $\begin{array}{c}1 \leq \mathrm{UACR}<3.5 \\
(\mathrm{~g} / \mathrm{g} \mathrm{Cr})\end{array}$ & $\begin{array}{c}\text { UACR } \geq 3.5 \\
\text { (g/g Cr) }\end{array}$ & P-value & $\begin{array}{c}\mathrm{eGFR} \geq 60 \\
(\mathrm{~mL} / \mathrm{min} / 1.7 \\
\left.3 \mathrm{~m}^{2}\right)\end{array}$ & $\begin{array}{c}\mathrm{eGFR}<60 \\
(\mathrm{~mL} / \mathrm{min} / 1.73 \\
\left.\mathrm{m}^{2}\right)\end{array}$ & $\begin{array}{c}\text { P- } \\
\text { value }\end{array}$ \\
\hline $\mathrm{N}$ & 304 & $204(66.9 \%)$ & $89(29.2 \%)$ & $11(3.6 \%)$ & & $167(54.8 \%)$ & $137(45.2 \%)$ & \\
\hline Men (\%) & $201(66.1 \%)$ & $144(70.6 \%)$ & $48(53.9 \%)$ & $9(81.8 \%)$ & 0.019 & $108(64.7 \%)$ & $93(67.9 \%)$ & 0.556 \\
\hline Age (years) & $49 \pm 15.3$ & $49 \pm 15.3$ & $48 \pm 15.1$ & $52 \pm 16.9$ & 0.626 & $45 \pm 14.9$ & $54 \pm 14.2$ & $<0.001$ \\
\hline Diabetes (\%) & $51(16.7 \%)$ & $22(10.8 \%)$ & $24(26.9 \%)$ & $5(45.5 \%)$ & $<0.001$ & $18(10.8 \%)$ & $33(23.9 \%)$ & 0.002 \\
\hline SBP (mmHg) & $122 \pm 15.4$ & $121 \pm 14.2$ & $123 \pm 14.7$ & $135 \pm 33.9$ & 0.013 & $120 \pm 13.4$ & $124 \pm 17.2$ & 0.023 \\
\hline DBP (mmHg) & $74 \pm 12.4$ & $74 \pm 12.4$ & $76 \pm 12.7$ & $74 \pm 15.7$ & 0.267 & $74 \pm 12.7$ & $75 \pm 11.9$ & 0.289 \\
\hline eGFR (mL/min/1.73 $\left.\mathrm{m}^{2}\right)$ & $64 \pm 38.5$ & $66 \pm 36.9$ & $62 \pm 42.1$ & $46 \pm 33.8$ & 0.176 & $100 \pm 33.8$ & $38 \pm 12.3$ & $<0.001$ \\
\hline $\mathrm{UACR}$ (mg/g Cr) & $944 \pm 925.5$ & $439 \pm 276.7$ & $1974 \pm 932.0$ & $4090 \pm 815.1$ & $<0.001$ & $869 \pm 762.0$ & $1035 \pm 1088.3$ & 0.135 \\
\hline Potassium (mg/dL) & $4.4 \pm 0.52$ & $4.3 \pm 0.50$ & $4.5 \pm 0.55$ & $4.6 \pm 0.43$ & 0.080 & $4.2 \pm 0.38$ & $4.6 \pm 0.55$ & $<0.001$ \\
\hline Aldosterone $(\mathrm{pg} / \mathrm{mL})$ & $76 \pm 93.2$ & $87.3 \pm 105.5$ & $62.3 \pm 73.0$ & $30.4 \pm 33.0$ & 0.032 & $62.9 \pm 73.79$ & $93.1 \pm 110.56$ & 0.007 \\
\hline
\end{tabular}

[3]. Patients were also divided into two groups according to their eGFR (eGFR $\geq 60 \mathrm{~mL} / \mathrm{min} / 1.73 \mathrm{~m}^{2}$ [N=167, $54.8 \%]$ and eGFR $<60 \mathrm{~mL} / \mathrm{min} / 1.73 \mathrm{~m}^{2}$ [N=137, 45.2\%]), and into three groups according to the degree of albuminuria (UACR <1g/g Cr, [N=204, 66.9\%], $1 \leq \mathrm{UACR}<3.5 \mathrm{~g} / \mathrm{g} \mathrm{Cr}$, [N=89, 29.2\%], and UACR $\geq 3.5 \mathrm{~g} / \mathrm{g} \mathrm{Cr}$, $[\mathrm{N}=11,3.6 \%])$.

\section{Statistical analyses}

Analyses were performed using SPSS 18.0.0 (SPSS Inc., Chicago, IL, USA). Normally distributed variables are reported as mean with standard deviations and compared using Student's t-test and categorical variables as proportions or ratios. The baseline characteristics of the study participants were compared using independent t-test or chi-square, where appropriate. Within-group changes of outcome variables after 6 and 12 months were assessed using paired t-test. P-values $<0.05$ were considered significant.

\section{Results}

\section{Baseline characteristics of patients}

304 patients (men $66.1 \%$, age $49 \pm 15.3$ years) were divided into two groups according to the degree of albuminuria, renal insufficiency, and aldosterone escape (Table 1). Patients with $1 \leq \mathrm{UACR}<3.5 \mathrm{~g} / \mathrm{g} \mathrm{Cr}$ and UACR $\geq 3.5 \mathrm{~g} / \mathrm{g} \mathrm{Cr}$ had a higher systolic blood pressure, higher incidence of pre-existing diabetes, and lower serum aldosterone level than patients with UACR $<1 \mathrm{~g} / \mathrm{g}$ Cr. Patients with eGFR $\geq 60 \mathrm{~mL} / \mathrm{min} / 1.73 \mathrm{~m}^{2}$ were younger and had lower systolic blood pressure, serum potassium level, and serum aldosterone level. The patients with aldosterone escape had a lower incidence of pre-existing diabetes and lower UACR.

\section{Changes in clinical variables after add-on spironolactone}

Table 2 lists the baseline systolic and diastolic blood pressure, eGFR, serum creatinine, UACR, and serum potassium in all patients, in patients with $1 \leq \mathrm{UACR}<3.5 \mathrm{~g} / \mathrm{g} \mathrm{Cr}$ and UACR $\geq 3.5 \mathrm{~g} / \mathrm{g} \mathrm{Cr}$, and in patients with eGFR $\geq 60 \mathrm{~mL} / \mathrm{min} / 1.73 \mathrm{~m}^{2}$ and at 6 months and 12 months after add-on spironolactone. In the group with $1 \leq \mathrm{UACR}<3.5 \mathrm{~g} / \mathrm{g} \mathrm{Cr}$ and UACR $\geq 3.5 \mathrm{~g} / \mathrm{g} \mathrm{Cr}$ or eGFR $\geq 60 \mathrm{~mL} / \mathrm{min} / 1.73 \mathrm{~m}^{2}$, the UACR at 6 months and 12 months showed a significant decline compared to the baseline levels (Fig. $1 \mathrm{~A}, \mathrm{~B}$ ). In terms of the degree of proteinuria reduction, patients with UACR $\geq 3.5 \mathrm{~g} / \mathrm{g}$ Cr showed greater reduction than patients with $1 \leq \mathrm{UACR}<3.5 \mathrm{~g} / \mathrm{g}$ $\mathrm{Cr}$ (reduction rate of UACR at 12 months; $57.2 \%$ in patients with UACR $\geq 3.5 \mathrm{~g} / \mathrm{g}$ Cr vs. $29.7 \%$ in patients with $1 \leq \mathrm{UACR}<3.5 \mathrm{~g} / \mathrm{g} \mathrm{Cr}$ ) Figure 1 shows that the patients with UACR $<1 \mathrm{~g} / \mathrm{g} \mathrm{Cr}$ or eGFR $<60 \mathrm{~mL} / \mathrm{min} / 1.73 \mathrm{~m}^{2}$ or aldosterone escape did not demonstrate significant reduction in UACR. All groups showed a significant decline in the eGFR and serum creatinine over a period of 12 months. The anti-proteinuric effect of spironolactone has varied depending on diabetes in patients with eGFR $\geq 60 \mathrm{~mL} / \mathrm{min} / 1.73 \mathrm{~m}^{2}$. UACR was significantly reduced at 


\section{Kidney \\ Blood Pressure Research}

6 months in patients with diabetes and eGFR $\geq 60$ $\mathrm{mL} / \mathrm{min} / 1.73 \mathrm{~m}^{2}$, but not in those without diabetes (Fig. 1 D).

Comparison between aldosterone escape group and aldosterone non-escape group

As shown in Table 3, there was a difference in the incidence of diabetes and UACR between the aldosterone escape group and aldosterone non-escape group at baseline. After 6 months and 12 months, the systolic and diastolic blood pressures were not significantly different from baseline. UACR
Table 2. Changes in the main clinical parameters before and after treatment with spironolactone

\begin{tabular}{|c|c|c|c|c|c|}
\hline Variable & Baseline & 6 months & 12 months & $\begin{array}{c}\text { P- } \\
\text { value }\end{array}$ & $\begin{array}{c}\text { P- } \\
\text { value }\end{array}$ \\
\hline \multicolumn{6}{|l|}{ SBP (mmHg) } \\
\hline All patients & $122 \pm 15.4$ & $119 \pm 15.7$ & $120 \pm 13.9$ & 0.038 & 0.239 \\
\hline $1 \leq \mathrm{UACR}<3.5(\mathrm{~g} / \mathrm{g} \mathrm{Cr})$ & $122 \pm 14.4$ & $118 \pm 15.9$ & $123 \pm 14.5$ & 0.062 & 0.886 \\
\hline $\mathrm{UACR} \geq 3.5(\mathrm{~g} / \mathrm{g} \mathrm{Cr})$ & $135 \pm 31.2$ & $137 \pm 36.7$ & $136 \pm 30.7$ & 0.166 & 0.533 \\
\hline $\mathrm{eGFR} \geq 60\left(\mathrm{~mL} / \mathrm{min} / 1.73 \mathrm{~m}^{2}\right)$ & $120 \pm 13.4$ & $117 \pm 14.5$ & $117 \pm 12.9$ & 0.302 & 0.529 \\
\hline \multicolumn{6}{|l|}{$\mathrm{DBP}(\mathrm{mmHg})$} \\
\hline All patients & $74 \pm 12.4$ & $73 \pm 13.2$ & $74 \pm 13.1$ & 0.195 & 0.732 \\
\hline $1 \leq \mathrm{UACR}<3.5(\mathrm{~g} / \mathrm{g} \mathrm{Cr})$ & $76 \pm 12.2$ & $74 \pm 12.2$ & $75 \pm 14.1$ & 0.142 & 0.860 \\
\hline UACR $\geq 3.5(\mathrm{~g} / \mathrm{g} \mathrm{Cr})$ & $74 \pm 15.7$ & $78 \pm 19.5$ & $76 \pm 11.9$ & 0.356 & 0.815 \\
\hline $\mathrm{eGFR} \geq 60\left(\mathrm{~mL} / \mathrm{min} / 1.73 \mathrm{~m}^{2}\right)$ & $74 \pm 12.7$ & $71 \pm 12.4$ & $73 \pm 13.1$ & 0.337 & 0.853 \\
\hline \multicolumn{6}{|l|}{ eGFR $\left(\mathrm{mL} / \mathrm{min} / 1.73 \mathrm{~m}^{2}\right)$} \\
\hline All patients & $72 \pm 40.9$ & $67 \pm 41.2$ & $61 \pm 36.7$ & 0.006 & $<0.001$ \\
\hline $1 \leq \mathrm{UACR}<3.5(\mathrm{~g} / \mathrm{g} \mathrm{Cr})$ & $65 \pm 37.9$ & $60 \pm 40.4$ & $47 \pm 28.9$ & 0.021 & $<0.001$ \\
\hline UACR $\geq 3.5(\mathrm{~g} / \mathrm{g} \mathrm{Cr})$ & $57 \pm 34.9$ & $56 \pm 50.1$ & $49 \pm 43.9$ & 0.001 & $<0.001$ \\
\hline $\mathrm{eGFR} \geq 60\left(\mathrm{~mL} / \mathrm{min} / 1.73 \mathrm{~m}^{2}\right)$ & $100 \pm 33.8$ & $95 \pm 36.3$ & $86 \pm 32.4$ & 0.877 & 0.156 \\
\hline \multicolumn{6}{|l|}{ Creatinine (mg/dL) } \\
\hline All patients & $1.4 \pm 0.71$ & $1.5 \pm 0.80$ & $1.6 \pm 0.95$ & $<0.001$ & $<0.001$ \\
\hline $1 \leq \mathrm{UACR}<3.5(\mathrm{~g} / \mathrm{g} \mathrm{Cr})$ & $1.5 \pm 0.78$ & $1.7 \pm 0.85$ & $1.9 \pm 0.81$ & 0.033 & $<0.001$ \\
\hline UACR $\geq 3.5(\mathrm{~g} / \mathrm{g} \mathrm{Cr})$ & $1.5 \pm 0.54$ & $1.8 \pm 0.74$ & $2.0 \pm 0.82$ & 0.046 & 0.009 \\
\hline $\mathrm{eGFR} \geq 60\left(\mathrm{~mL} / \mathrm{min} / 1.73 \mathrm{~m}^{2}\right)$ & $0.9 \pm 0.22$ & $0.9 \pm 0.26$ & $1.0 \pm 0.30$ & $<0.001$ & $<0.001$ \\
\hline \multicolumn{6}{|l|}{ UACR (mg/g Cr) } \\
\hline All patients & $944 \pm 925.5$ & $762 \pm 838.3$ & $678 \pm 932.6$ & 0.007 & 0.001 \\
\hline $1 \leq \mathrm{UACR}<3.5(\mathrm{~g} / \mathrm{g} \mathrm{Cr})$ & $1638 \pm 499.3$ & $1301 \pm 894.4$ & $1151 \pm 5032.1$ & $<0.001$ & 0.001 \\
\hline UACR $\geq 3.5(\mathrm{~g} / \mathrm{g} \mathrm{Cr})$ & $4084 \pm 625.7$ & $2827 \pm 1472.2$ & $1744 \pm 1092.0$ & 0.036 & 0.001 \\
\hline $\mathrm{eGFR} \geq 60\left(\mathrm{~mL} / \mathrm{min} / 1.73 \mathrm{~m}^{2}\right)$ & $869 \pm 762.0$ & $661 \pm 758.9$ & $561 \pm 736.2$ & 0.049 & 0.002 \\
\hline \multicolumn{6}{|l|}{ Potassium $(\mathrm{mEq} / \mathrm{L})$} \\
\hline All patients & $4.4 \pm 0.52$ & $4.7 \pm 0.68$ & $4.7 \pm 0.69$ & $<0.001$ & $<0.001$ \\
\hline $1 \leq \mathrm{UACR}<3.5(\mathrm{~g} / \mathrm{g} \mathrm{Cr})$ & $4.5 \pm 0.55$ & $4.8 \pm 0.77$ & $5.2 \pm 0.75$ & $<0.001$ & $<0.001$ \\
\hline UACR $\geq 3.5$ (g/g Cr) & $4.6 \pm 0.44$ & $5.0 \pm 0.95$ & $5.0 \pm 0.78$ & 0.205 & 0.125 \\
\hline $\mathrm{eGFR} \geq 60\left(\mathrm{~mL} / \mathrm{min} / 1.73 \mathrm{~m}^{2}\right)$ & $4.2 \pm 0.38$ & $4.4 \pm 0.48$ & $4.4 \pm 0.51$ & $<0.001$ & $<0.001$ \\
\hline
\end{tabular}

Data are presented as mean \pm SD; SBP, systolic blood pressure; DBP, diastolic blood pressure; eGFR, estimated glomerular filtration rate; UACR, urine albumin to creatinine ratio; §: comparison between

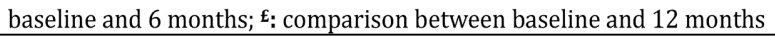

was significantly decreased in the aldosterone non-escape group, but not in the aldosterone escape group. The plasma renin activity was significantly increased in both the aldosterone non-escape group and aldosterone escape group (Table 3).

\section{Adverse events associated with spironolactone}

Hyperkalemia, gynecomastia, hypotension, and gastrointestinal distress were reported as the side effects of spironolactone during the 12 months of administration. If the patient developed hyperkalemia $(\mathrm{K} \geq 5.5 \mathrm{mEq} / \mathrm{L})$, potassium lowering medication was initiated, and if the hyperkalemia was severe $(\mathrm{K} \geq 7.0 \mathrm{mEq} / \mathrm{L})$ [4], the spironolactone treatment was discontinued. Fifty-one patients (16.7\%) with $\mathrm{K} \geq 5.5 \mathrm{mEq} / \mathrm{L}$ were treated using gastrointestinal ion exchange with oral sodium polystyrene sulfonate for lowering potassium. Nine of the 137 patients with eGFR $<60 \mathrm{~mL} / \mathrm{min} / 1.73 \mathrm{~m}^{2}(6.5 \%)$ and none of the 167 patients with eGFR $\geq 60 \mathrm{~mL} / \mathrm{min} / 1.73 \mathrm{~m}^{2}$ developed severe hyperkalemia. Gynecomastia occurred in 8 of the 137 patients with eGFR $<60 \mathrm{~mL} / \mathrm{min} / 1.73 \mathrm{~m}^{2}(5.8 \%)$ and in 2 of the 167 patients with eGFR $\geq 60 \mathrm{~mL} / \mathrm{min} / 1.73 \mathrm{~m}^{2}(1.2 \%$ ) (Figure 2 ). 


\section{Kidney \\ Blood Pressure \\ Research}

Table 3. Patient characteristics before and after spironolactone therapy in the absence (non-escape group) and presence (escape group) of aldosterone escape

\begin{tabular}{|c|c|c|c|c|c|c|c|c|}
\hline \multirow{2}{*}{ Variable } & \multicolumn{4}{|c|}{ Non-escape group $(\mathrm{N}=209)$} & \multicolumn{4}{|c|}{ Escape group $(\mathrm{N}=95)$} \\
\hline & Baseline & 6 months & 12 months & P-value & Baseline & 6 months & 12 months & P-value \\
\hline SBP (mmHg) & $122 \pm 16.0$ & $119 \pm 16.1$ & $121 \pm 13.9$ & 0.627 & $122 \pm 14.0$ & $118 \pm 14.8$ & $118 \pm 14.0$ & 0.146 \\
\hline $\mathrm{DBP}(\mathrm{mmHg})$ & $74 \pm 12.4$ & $74 \pm 12.8$ & $74 \pm 12.4$ & 0.796 & $75 \pm 12.3$ & $71 \pm 14.2$ & $74 \pm 14.4$ & 0.823 \\
\hline eGFR* & $75 \pm 40.4$ & $70 \pm 41.8$ & $63 \pm 37.7$ & $<0.001$ & $67 \pm 41.5$ & $61 \pm 39.2$ & $57 \pm 33.9$ & 0.004 \\
\hline UACR (mg/g) & $1051 \pm 989.2$ & $860 \pm 917.0$ & $734 \pm 1001$ & 0.002 & $707 \pm 716.4$ & $535 \pm 562.5$ & $553 \pm 750.9$ & 0.336 \\
\hline Potassium (mEq/L) & $4.3 \pm 0.52$ & $4.7 \pm 0.73$ & $4.7 \pm 0.70$ & $<0.001$ & $4.4 \pm 0.50$ & $4.6 \pm 0.58$ & $4.8 \pm 0.65$ & 0.000 \\
\hline Aldosterone $(\mathrm{pg} / \mathrm{mL})$ & $36.2 \pm 20.89$ & $124 \pm 123.2$ & $173 \pm 169.7$ & $<0.001$ & $165.1 \pm 124.52$ & $221 \pm 166.8$ & $232 \pm 179.1$ & 0.014 \\
\hline Plasma renin activity** & $5.25 \pm 7.42$ & $10.3 \pm 9.11$ & $12.8 \pm 11.6$ & $<0.001$ & $12.1 \pm 5.45$ & $11.4 \pm 12.3$ & $14.5 \pm 13.3$ & 0.001 \\
\hline
\end{tabular}

Data are presented as mean \pm SD; SBP, systolic blood pressure; DBP, diastolic blood pressure; eGFR, estimated glomerular filtration; UACR, urine albumin to creatinine ratio; P-value: for a comparison between baseline and $\left.12 \mathrm{months} ;{ }^{*}(\mathrm{~mL} / \mathrm{min} / 1.73 \mathrm{~m})^{2}\right) * *(\mathrm{ng} / \mathrm{mL} / \mathrm{h})$

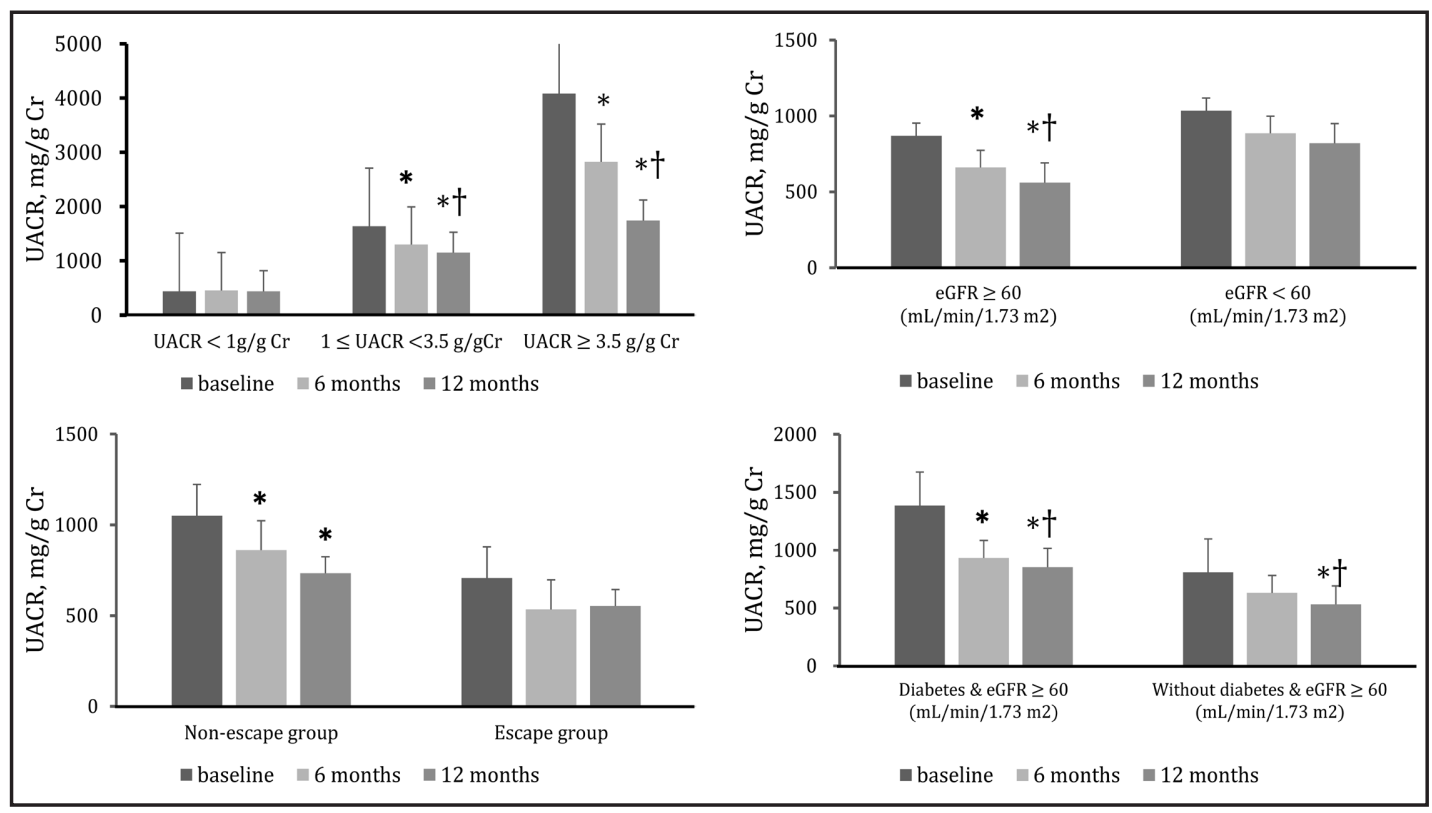

Fig. 1. Mean changes in the urine albumin-to-creatinine ratio over 12 months. ${ }^{*}$ compared to baseline. $\dagger$ compared to 6 months.

\section{Discussion}

It is well known that aldosterone increases sodium and water reabsorption in the distal nephron and promotes tubular secretion of potassium [5]. Aldosterone also plays a major role in the regulation of the vasculature and has been associated with vascular smooth muscle cell hypertrophy, endothelial dysfunction, high blood pressure, proteinuria, and renal vascular injury [6]. For this

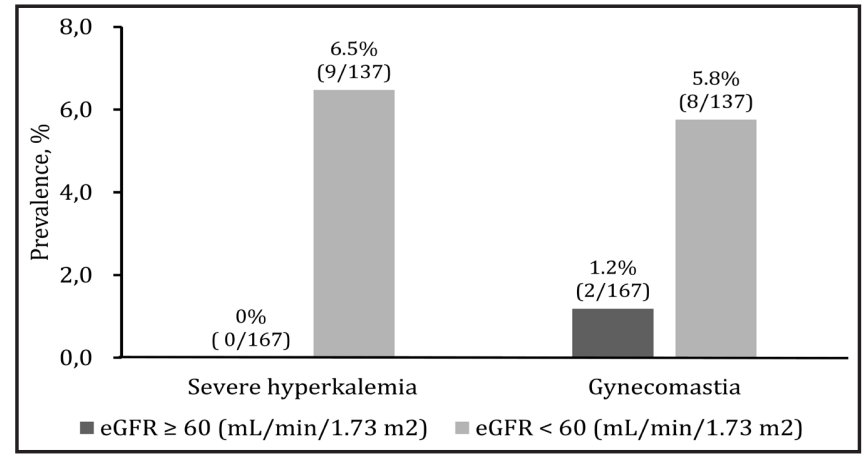

Fig. 2. Adverse events associated with spironolactone. Severe hyperkalemia indicates a serum potassium level $\geq 7.0 \mathrm{mEq} / \mathrm{L}$. reason, we expected the aldosterone escape group to show a greater reduction in proteinuria after spironolactone was added to the treatment. Spironolactone is known to reduce proteinuria in CKD patients; however, it carries the risk of hyperkalemia and decreased 


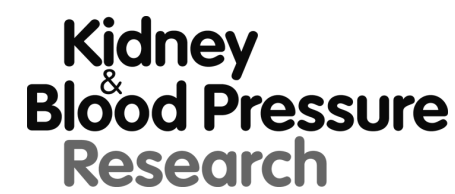

\begin{tabular}{l|l}
\hline Kidney Blood Press Res 2014;39:573-580 \\
\hline $\begin{array}{l}\text { DOI: } 10.1159 / 000368470 \\
\text { Published onlıne: December 15, } 2014\end{array}$ & $\begin{array}{l}\text { C 2 2014 S. Karger AG, Basel } \\
\text { www.karger.com/kbr }\end{array}$ \\
\hline
\end{tabular} 578

eGFR. The indications for an add-on aldosterone blockade in patients with proteinuria have not yet been established. If the effect of treatment were different depending on serial aldosterone levels, measurement of serum aldosterone level might be helpful guide for the clinicians to decide to add on treatment of spironolactone. Our analysis revealed that an add-on spironolactone treatment was more effective in the aldosterone non-escape group compared to the aldosterone escape group. This is not in agreement with the results of a previous study, which found that the higher the plasma aldosterone level, the greater the anti-proteinuria in response to an aldosterone antagonist [1, 7]. Sato et al suggest that every patient with proteinuria and aldosterone escape should be treated prophylactically with an aldosterone antagonist [8]. Interestingly, recent studies have indicated that MR activation is important in the pathogenesis of cardiovascular and renal damage not only at the highaldosterone status but also for low-aldosterone hypertension $[9,10]$. In the present study, the aldosterone non-escape group had a higher incidence of diabetes and proteinuria, and these factors may be associated with the differences in the effects of spironolactone between the aldosterone escape and non-escape groups. Based on subgroup analysis, the present study revealed that under the same eGFR conditions (eGFR $\geq 60 \mathrm{~mL} / \mathrm{min} / 1.73 \mathrm{~m}^{2}$ ), the effect of proteinuria reduction was more prominent in patients with diabetes than in those without diabetes. Therefore, serum aldosterone level is probably not a crucial factor because the degree of proteinuria reduction was not associated with the serum aldosterone concentration $(\mathrm{r}=-0.051, \mathrm{P}=0.456)$.

Shibata et al. reported that podocytes were involved in the early glomerular damage seen in aldosterone-infused rats due to reactive oxygen species (ROS) and that spironolactone could be helpful in the recovery from podocyte injury [11]. In addition, other studies have demonstrated high glucose-induced expression of $S g K 1$ through MR, which is upregulated in patients with diabetic nephropathy and have also demonstrated the activation of nicotinamide adenine dinucleotide phosphate oxidase and ROS production, which induced podocyte apoptosis and loss of function in in vivo and in vitro studies. Spironolactone inhibited all these effects by reducing tumor growth factor- $\beta$ mRNA and by reducing renal fibrosis [12]. Spironolactone helps reduce the serum aldosterone level, and it affects the podocytes directly by diminishing the production of ROS. In this context, after spironolactone treatment, proteinuria was decreased in the patients with $1 \leq \mathrm{UACR}<3.5 \mathrm{~g} / \mathrm{g}$ Cr and UACR $\geq 3.5$ $\mathrm{g} / \mathrm{g} \mathrm{Cr}$ under the condition of podocyte injury. The present study showed that proteinuria reduction was more prominent in patients with eGFR $\geq 60 \mathrm{~mL} / \mathrm{min} / 1.73 \mathrm{~m}^{2}$. We can therefore speculate that aldosterone antagonists may have anti-proteinuric and renoprotective effects only in the early stages of kidney damage and not in the advanced stage of renal failure. In accordance with previous studies [1], patients with eGFR $<60 \mathrm{~mL} / \mathrm{min} / 1.73 \mathrm{~m}^{2}$ were at a higher risk for severe hyperkalemia. While 9 patients with eGFR $<60 \mathrm{~mL} / \mathrm{min} / 1.73 \mathrm{~m}^{2}$ experienced severe hyperkalemia and discontinued the use of spironolactone, none of the patients with eGFR $<60 \mathrm{~mL} / \mathrm{min} / 1.73 \mathrm{~m}^{2}$ experienced severe hyperkalemia. Taken together, an aldosterone antagonist can be recommended for patients with eGFR $\geq 60 \mathrm{~mL} / \mathrm{min} / 1.73$ $\mathrm{m}^{2}$ because of the low risk of hyperkalemia associated with its use.

The renin-angiotensin system (RAS) plays a central role in renal pathophysiology. Therefore, an extensive blockade of the RAS with an ACEI and ARB was expected to be more beneficial in renal disease; however, there is limited evidence regarding the effects of dual RAS inhibition. In the ONTARGET study, it was found that dual RAS inhibition in patients at high risk of cardiovascular events did not improve cardiovascular outcomes and led to an increased incidence of renal events due to acute renal failure $[13,14]$. In addition, another previous study on patients with diabetes and overt proteinuria, who received the dual therapy with ACEI and ARB, was terminated early due to a greater number of observed acute kidney injury events and hyperkalemia [15]. In order to overcome the limitation of dual RAS inhibition with ACEI and ARB, many clinical studies have been conducted recently to investigate the efficacy of MR antagonists in reducing proteinuria and attenuating progressive renal disease [16]. 


\section{Kidney \\ Blood Pressure Research}

A progressive decline in eGFR was observed in all groups, which is consistent with previous observations [17-19]. The proportion of patients that experienced a rise of $30 \%$ above baseline in serum creatinine after a median of 34 days was 39.1\% [18]. In another study of 136 patients, the eGFR showed a decline from 74.39 to $64.16 \mathrm{~mL} / \mathrm{min} / 1.73 \mathrm{~m}^{2}$ after 12 months of treatment with spironolactone [19]. Our data revealed that the eGFR reduces by about $18 \mathrm{~mL} / \mathrm{min} / 1.73 \mathrm{~m}^{2}$ in patients with $1 \leq \mathrm{UACR}<3.5 \mathrm{~g} / \mathrm{g}$ creatinine, which is higher than the finding of previous studies however, this reduction seems to be transient and could be restored. In a previous study with an observational period of 48 months, the eGFR was shown to recover [20]. Additionally, the discrepancy in the degree of the declining eGFR among different studies could be due to the differences in the dosage of spironolactone, duration of treatment, and baseline characteristics including age, underlying disease, and racial and ethnic disparities. While the mechanisms underlying this early decline remain mostly obscure, it seems to be associated with hemodynamic alterations caused by suppression of genomic effects by aldosterone $[18,21]$. This was estimated to be the hemodynamic effect of preventing vasoconstriction and reducing the blood volume of aldosterone antagonist, and impairment of renal auto-regulation $[22,23]$.

\section{Conclusion}

The clinical implication of our findings is that adding spironolactone to ACEIs or ARBs may have an additional benefit in patients with persisting proteinuria, who have an eGFR $\geq 60 \mathrm{~mL} / \mathrm{min} / 1.73 \mathrm{~m}^{2}$, or UACR $\geq 1 \mathrm{~g} / \mathrm{g} \mathrm{Cr}$, or belong to the aldosterone non-escape group.

\section{Disclosure Statement}

All the authors have no conflicts of interest to declare.

\section{Acknowledgments}

This study was supported by a grant (CRI13903-21) Chonnam National University Hospital Biomedical Research Institute.

\section{References}

$\checkmark$ Bomback AS, Kshirsagar AV, Amamoo MA, Klemmer PJ: Change in proteinuria after adding aldosterone blockers to ACE inhibitors or angiotensin receptor blockers in CKD: a systematic review. Am J Kidney Dis 2008;51:199-211.

-2 Levey AS, Stevens LA, Schmid CH, Zhang YL, Castro AF, 3rd, Feldman HI, Kusek JW, Eggers P, Van Lente F, Greene T, Coresh J: A new equation to estimate glomerular filtration rate. Ann Intern Med 2009;150:604612.

- 3 Lee AF, MacFadyen RJ, Struthers AD: Neurohormonal reactivation in heart failure patients on chronic ACE inhibitor therapy: a longitudinal study. Eur J Heart Fail 1999;1:401-406.

-4 Mandal AK: Hypokalemia and hyperkalemia. Med Clin North Am 1997;81:611-639.

-5 Granger JP, Kassab S, Novak J, Reckelhoff JF, Tucker B, Miller MT: Role of nitric oxide in modulating renal function and arterial pressure during chronic aldosterone excess. Am J Physiol 1999;276:R197-202.

-6 Lakkis J, Lu WX, Weir MR: RAAS escape: a real clinical entity that may be important in the progression of cardiovascular and renal disease. Curr Hypertens Rep 2003;5:408-417.

7 Bianchi S, Bigazzi R, Campese VM: Antagonists of aldosterone and proteinuria in patients with CKD: an uncontrolled pilot study. Am J Kidney Dis 2005;46:45-51. 


\section{Kidney \\ Blood Pressure Research}

\begin{tabular}{l|l}
\hline Kidney Blood Press Res 2014;39:573-580 \\
\hline DOI: $10.1159 / 000368470$ \\
\begin{tabular}{l|l} 
Publisned onlIne: December 15, 2014 & (C)14 S. Karger AG, Basel \\
www.karger.com/kbr
\end{tabular} \\
\hline
\end{tabular}

Kim/Bae/Ma/Kim: Spironolactone for Proteinuria

8 Nishiyama A, Kobori H, Konishi Y, Morikawa T, Maeda I, Okumura M, Kishida M, Hamada M, Nagai Y, Nakagawa T, Ohashi N, Nakano D, Hitomi H, Imanishi M: Mineralocorticoid receptor blockade enhances the antiproteinuric effect of an angiotensin II blocker through inhibiting podocyte injury in type 2 diabetic rats. J Pharmacol Exp Ther 2010;332:1072-1080.

-9 Nagase M, Shibata S, Yoshida S, Nagase T, Gotoda T, Fujita T: Podocyte injury underlies the glomerulopathy of Dahl salt-hypertensive rats and is reversed by aldosterone blocker. Hypertension 2006;47:1084-1093.

10 Nagata K, Obata K, Xu J, Ichihara S, Noda A, Kimata H, Kato T, Izawa H, Murohara T, Yokota M: Mineralocorticoid receptor antagonism attenuates cardiac hypertrophy and failure in low-aldosterone hypertensive rats. Hypertension 2006;47:656-664.

11 Shibata S, Nagase M, Yoshida S, Kawachi H, Fujita T: Podocyte as the target for aldosterone: roles of oxidative stress and Sgk1. Hypertension 2007;49:355-364.

-12 Toyonaga J, Tsuruya K, Ikeda H, Noguchi H, Yotsueda H, Fujisaki K, Hirakawa M, Taniguchi M, Masutani K, Iida M: Spironolactone inhibits hyperglycemia-induced podocyte injury by attenuating ROS production. Nephrol Dial Transplant 2011;26:2475-2484.

13 Yusuf S, Teo KK, Pogue J, Dyal L, Copland I, Schumacher H, Dagenais G, Sleight P, Anderson C: Telmisartan, ramipril, or both in patients at high risk for vascular events. N Engl J Med 2008;358:1547-1559.

14 Mann JF, Schmieder RE, McQueen M, Dyal L, Schumacher H, Pogue J, Wang X, Maggioni A, Budaj A, Chaithiraphan S, Dickstein K, Keltai M, Metsarinne K, Oto A, Parkhomenko A, Piegas LS, Svendsen TL, Teo KK, Yusuf S: Renal outcomes with telmisartan, ramipril, or both, in people at high vascular risk (the ONTARGET study): a multicentre, randomised, double-blind, controlled trial. Lancet 2008;372:547-553.

-15 Fried LF, Duckworth W, Zhang JH, O'Connor T, Brophy M, Emanuele N, Huang GD, McCullough PA, Palevsky PM, Seliger S, Warren SR, Peduzzi P: Design of combination angiotensin receptor blocker and angiotensinconverting enzyme inhibitor for treatment of diabetic nephropathy (VA NEPHRON-D). Clin J Am Soc Nephrol 2009;4:361-368.

-16 Shavit L, Lifschitz MD, Epstein M: Aldosterone blockade and the mineralocorticoid receptor in the management of chronic kidney disease: current concepts and emerging treatment paradigms. Kidney Int 2012;81:955-968.

17 Rossing K, Schjoedt KJ, Smidt UM, Boomsma F, Parving HH: Beneficial effects of adding spironolactone to recommended antihypertensive treatment in diabetic nephropathy: a randomized, double-masked, crossover study. Diabetes Care 2005;28:2106-2112.

18 Khosla N, Kalaitzidis R, Bakris GL: Predictors of hyperkalemia risk following hypertension control with aldosterone blockade. Am J Nephrol 2009;30:418-424.

19 Esteghamati A, Noshad S, Jarrah S, Mousavizadeh M, Khoee SH, Nakhjavani M: Long-term effects of addition of mineralocorticoid receptor antagonist to angiotensin II receptor blocker in patients with diabetic nephropathy: a randomized clinical trial. Nephrol Dial Transplant 2013;28:2823-2833.

-20 Morales E, Millet VG, Rojas-Rivera J, Huerta A, Gutierrez E, Gutierrez-Solis E, Egido J, Praga M: Renoprotective effects of mineralocorticoid receptor blockers in patients with proteinuric kidney diseases. Nephrol Dial Transplant 2013;28:405-412.

21 Bianchi S, Bigazzi R, Campese VM: Long-term effects of spironolactone on proteinuria and kidney function in patients with chronic kidney disease. Kidney Int 2006;70:2116-2123.

-22 Bunda S, Wang Y, Mitts TF, Liu P, Arab S, Arabkhari M, Hinek A: Aldosterone stimulates elastogenesis in cardiac fibroblasts via mineralocorticoid receptor-independent action involving the consecutive activation of Galpha13, c-Src, the insulin-like growth factor-I receptor, and phosphatidylinositol 3-kinase/Akt. J Biol Chem 2009;284:16633-16647.

23 Ren Y, D'Ambrosio MA, Liu R, Pagano PJ, Garvin JL, Carretero OA: Enhanced myogenic response in the afferent arteriole of spontaneously hypertensive rats. Am J Physiol Heart Circ Physiol 2010;298:H17691775 . 